Transnational Business Governance Interactions Project Working Paper No. 35

April 2019

\title{
Issue Control in Transnational Business Governance Interactions
}

\author{
Lasse Folke Henriksen and Leonard Seabrooke \\ Copenhagen Business School
}

This paper is available free of charge from www.tgiforum.org

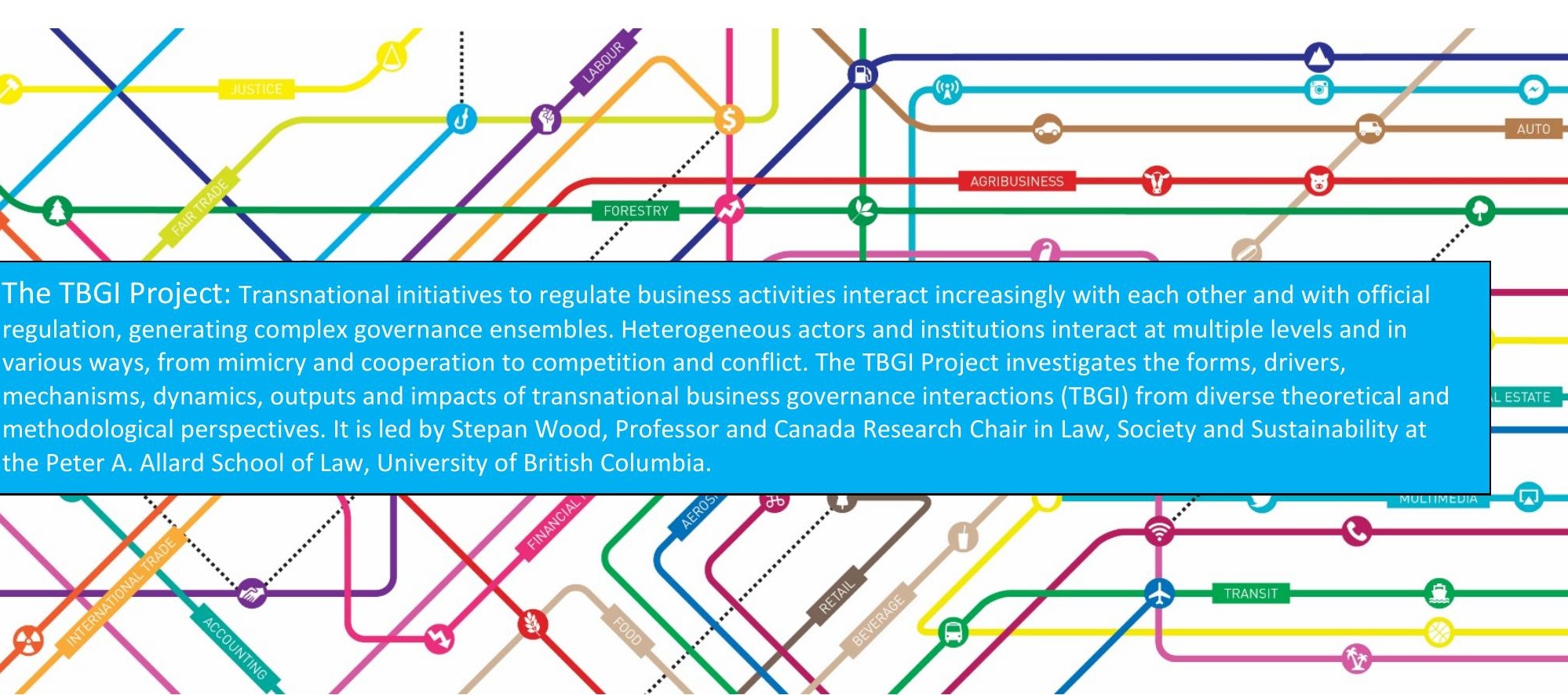


TBGI Project Working Paper No. 35

\title{
Issue Control in Transnational Business Governance Interactions
}

\author{
Lasse Folke Henriksen and Leonard Seabrooke ${ }^{1}$
}

\section{Abstract}

This chapter argues that two-level networks of issue professionals and organizations create the obstacles to better regulation and advancement of marginalized interests revealed by other chapters in the book. It identifies four such obstacles: gaps between policy design and implementation; competing interests within standard-setting bodies; power asymmetries in standards adoption; and professionals' desire for autonomy and issue control. It argues that these obstacles are outcomes of strategic behaviour by issue professionals who network to ensure they control governance of important issues. The chapter analyzes these interactions as a two-level network, comprised of inter-personal and inter-organizational networks. This analysis helps explain how regulatory capacities are developed and distributed, and why efforts to harness transnational business governance interactions (TBGIs) often falter.

\section{Keywords}

Issue professionals, two-level networks, transnational business governance interactions

\section{Introduction}

In this chapter we focus on the role of professional networks in transnational business governance interactions (TBGIs). Professional networks in many ways provide the context of interaction for issue-specific work within and across transnational business governance (TBG). Those setting the rules and standards in TBG, promulgating them and making sure they are implemented and evaluated increasingly consider themselves 'professionals'. This entails that work practices pertaining to all stages of the governance process move from being considered non-professional to undergoing some degree of professionalization. A field that is professional entails participants directing attention at each other as professional peers. This can evoke a sense of community and belonging around collective professional identities and mutual recognition around shared competencies and methodology. Professionalization in issue-specific governance fields can also, however, follow messier trajectories where expertise based on institutional experience becomes the driver of peer recognition. Studying the character and structure of the professional networks involved in TBGls is important to understand how these interactions play out and what their likely outcomes are. ${ }^{i}$

In this chapter we argue that people we call 'issue professionals' have risen as a prominent actor type within the institutionally hybrid fields of governance that we witness in transnational business

\footnotetext{
1 Lasse Folke Henriksen, Assistant Professor, Copenhagen Business School. Ifh.ioa@cbs.dk. Leonard Seabrooke, Professor, Copenhagen Business School. Ise.ioa@cbs.dk. A revised version of this paper is forthcoming in Stepan Wood et al., eds. Transnational Business Governance Interactions: Empowering Marginalized Actors and Enhancing Regulatory Quality. Cheltenham, UK: Edward Elgar.
} 
governance. These fields entail intense interactions between institutionally diverse actors, such as firms, NGO, states and international organizations, at one or several stages of the governance process. Issue professionals are actors who are seen as 'knowing well' within an issue-specific field of governance; recognition among their professional peers is often based on a combination of specialized technical expertise and institutional mobility (Seabrooke and Henriksen 2017).

The remainder of the chapter consists of four sections. Part 2 locates key hurdles to productive TBGIs that are identified by contributors to this volume. We suggest that there is some analytical purchase in addressing these hurdles via our professional-organizational nexus framework. Part 3 introduces this framework, based around the concept of issue professionals as an important ideal-type actor in transnational business governance. Part 4 elaborates further on our framework, locating the professional-organizational nexus, and examining issue control as an outcome of two-level network dynamics in TBGIs. Part 5 discusses how professional and organizational characteristics can be matched to identify where there are likely opportunities for issue professionals to make the most of their TBGIs.

\section{Transnational Business Governance Interactions}

This volume is concerned with a key question in international political economy and international law: how transnational business governance interactions can be organized and orchestrated in a way that advances marginalized actors, promotes sound environmental, financial and social standards, while also improving regulatory capacities. The promise of hybrid governance and non-state involvement in standardsetting is greater stakeholder engagement, accountability and transparency. This promise is difficult to keep, especially when those involved may have converged on a current interest but have prospects that diverge.

The contributors to this volume point to both the opportunities and frustrations professionals, policymakers and organizations face when trying to live up to this promise. In particular, they point to four key hurdles where TBGIs produced outcomes that deviated from good intentions. These hurdles arise when:

1. There are clear gaps between policy design and implementation;

2. Standard-setting bodies become arenas for competing interests;

3. There are clear power asymmetries in the adoption of standards and best practices; and

4. The interests of professionals involved in the interaction extend beyond the standard of concern to controlling the issue more generally.

These hurdles can be identified in several of the case-based contributions to this volume. First, Sophia Carodenuto and Benjamin Cashore (Chapter 10) demonstrate that the design of timber legality assurance systems was far removed from their targets, and that domestic implementation in Cameroon had negative effects on behavior like bribery. Phillip Paiement's study (Chapter 11) of the EU's Renewable Energy Directive (RED) shows that the voluntary basis for the monitoring of biomass production sites has permitted non-state actors to take liberties that undermine the regime for vulnerable parties. Differently, Jane Winn (Chapter 5 ) demonstrates via the case of payment systems that EU regulators have intervened in an excessive manner to force payments systems upgrading on the private sector.

Second, on how standard-setting bodies become arenas for competition, Paul Verbruggen and Tetty Havinga (Chapter 2) demonstrate that national governments have differed in their interactions with the Global Food Safety Initiative (GFSI), with some asserting a 'regulatory enrolment' strategy to pull non-state schemes into viewing issues their way. Similarly, Matthew Bach (Chapter 12) points to how the Oil \& Gas Climate Initiative $(\mathrm{OGCl})$ may have enrolled diverse actors to promote 'pro-innovation principles' that have regulatory effects, but its commitment as an organization is unclear - it is an arena for professional competition over the 'carbon-constrained' future of oil and gas, which allows those involved in the process to hedge against regulatory interventions while also acknowledging the need to lower their risks and uncertainties. 
Third, on power asymmetries, Donal Casey (Chapter 9) shows how the retailers that formed GLOBALGAP organized and produced strategies allowing the organization to dominate the issue, hampering more democratic initiatives. Paul Foley (Chapter 14) provides an account of how alternative and more progressive bodies working on ethical eco-certifications are in a structurally weak position compared to the Marine Stewardship Council (MSC), which then blocks progressive developments. Similarly, Simin Gao and Christopher Chen (Chapter 13) illustrate how in finance isomorphic pressures on the governance of derivatives trading were intense, while regional variation in the governance of futures trading was more possible. This state of affairs prevailed until the global financial crisis, when international pressures led to greater conformity around a common Western model.

Fourth, on the autonomy of professionals involved in controlling issues, Graeme Auld and Stefan Renckens (Chapter 6) show how the mobility of individual assessors involved with the MSC creates tensions with the audit firms and their work. The consequence of professional mobility is a destabilization of the functioning of the transnational body, with control over assessment knowledge fragmented. Furthermore, the prominence of professional mobility in different transnational interactions is, in part, a popularity contest. As Oliver Westerwinter (Chapter 7) clearly outlines, TBGIs produce a more crowded field on popular issues, such as the environment and development. Other issues are less attractive for such coordination, such as security (where states still rule), finance (where rents are high), and human rights (where large NGOs dominate).

These hurdles point to micro, meso, and macro-level phenomena that comprise the interactions in the framework for this volume (Eberlein et al. 2014). This volume adopts a broad notion of interactions to include steering mechanisms, consensus formation, and relationships where actors are drawn into regulatory schemes, be it through coercion, enrolment, or other means. Interactions can be both outcomes and casual factors, a notion that relaxes the idea that one always has to find the 'smoking gun' in discussing how regulation moves forward. This notion emphasizes that specifying change in the environment in which interactions take place is also important.

We suggest that our professional-organizational nexus framework can shine some light on the hurdles identified above: policy gaps, competition in standard-setting, power asymmetries, and professional autonomy. Focusing on how professionals operate in two-level professional and organizational networks can provide us with some insights into why policy gaps are common, what is at stake in standard-setting beyond the content of the standard, how power asymmetries are reinforced, and why professionals seek to maintain autonomy and not be beholden to particular organizations.

\section{Issue professionals}

Professionals are individuals with abstract higher-level learning and specific skill sets to address tasks (Abbott 1988). Doctors and lawyers come to mind when we characterize what is exceptional about professional work. We suggest that transnationally, professionalism is often linked more tightly to issues than to formal boundaries of professional groups (Seabrooke and Henriksen 2017). Recently scholars have noted how professionals have become more transnational and partially delinked from national professional associations (Seabrooke 2014; Carter et al. 2015; Harrington 2016; Brock 2016), while also maintaining selective ties to local networks (Dezalay and Garth 2016; Block et al. 2018; Spence et al. 2018).

We suggest that an 'issue professional' is a particular type of professional who is engaged in transnational organizing and is particularly important in determining how issues are treated and governed transnationally. Transnationality is important for issue professionals' capacity not to conform to defined jurisdictional roles common in a national context. Rather than being located in specific associations such as the American Medical Association or the like, these professionals combine knowledge and skills to enhance their attempts at control of a specific issue. Rather than relying on the conventional link between professionals and organizations in how issues are addressed (Noordegraaf 2011a), issue professionals actively foster professional and organizational networks in their attempts at issue control. 
Issue professionals are different from 'issue entrepreneurs' (Carpenter 2007). As a category, issue entrepreneur is used to provide an actor-based explanation of issue emergence. Issue professionals are not necessarily inventors of issues, but they are involved in generating, maintaining and defending attempts at issue control. There is also greater flexibility in how issue professionals determine their tasks in treating issues. Tasks include the modalities of action for professionals in how they classify, reason and take action on identified problems, or how they diagnose, infer, and treat their identified problems (Abbott 1988). Changes to tasks can occur through processes of professionalization, including demands to conduct work in particular ways, according to codes of ethics. Professionalization also entails treating professionalism as a capacity to manage and organize tasks rather than the knowledge and training that inform their execution (Faulconbridge and Muzio 2008; Evetts 2013). Issue professionals have particular tasks, but they are customized for the issue of concern rather than belonging to, and being reinforced by, one particular expert discipline. On issues that are highly technical and narrow, professional tasks and transnational issue control may go hand in hand (Ban et al. 2016). Transnational organizing on the severe acute respiratory syndrome (SARS) and bird flu crises provide an example, where medical experts aligned with international organizations to diagnose and treat the problems. Here 'classic' professional tasks were closely matched to how a transnational issue was treated (see also Nilsson 2017). By contrast, the emergence of 'multi-problems' has led to dilemmas when the relevant professions and the organizations needed do not align (Noordegraaf 2011b). In a domestic context, professional coordination can be made more difficult by jurisdictional battles over tasks and who is permitted to work on what issues. Transnationality matters here in liberating issue professionals to use their career experience and differing skills in a context in which domestic jurisdictions are not relied upon, can potentially be ignored, or are secondary in how issues are treated.

This is not to say that there are not struggles over who may work on what issues, but that issue professionals are not limited to the common domestic understanding of national professional jurisdictions. Issue professionals have a strong incentive to maintain their position within a network by excluding others who do not agree with their understanding of issues or threaten their resources. In some areas, such as financial reform, issue professionals behave according to prestige incentives and will be reluctant to introduce controversial ideas and topics in which they have little expertise, such as shadow banking, or political power, such as tax havens (Ban et al. 2016; Seabrooke and Wigan 2016; this dynamic may help explain the similarity of futures exchange governance design in Asia and the West: Gao and Chen, Chapter 13). Rather, they will control debates in a manner that confirms their affiliations and prestige networks (Seabrooke and Tsingou 2014). Similarly, professionals can network to ensure that knowledge production is controlled by them rather than by bureaucracies formally running the organization (Brivot, 2011; this dynamic may also be at work in SSCM: Meidinger, Chapter 3).

Investigating how professionals engage with their own peer networks and organizational networks is useful in considering how transnational organizing happens. We see transnational issues as organized through a professional-organizational nexus that is fruitfully conceived as a two-level network. We develop this idea further in the following section.

\section{The Professional-Organizational Nexus as a Two-Level Network}

We argue that a professional-organizational nexus is the key to explaining how TBGls play out. We provide a framework for understanding how professionals and organizations interact in transnational networks based on differentiating professional work roles and organizational types. This framework aligns closely with research that seeks to understand how professionals and other actors work in 'ecologies', be they 'linked ecologies' (Seabrooke and Tsingou 2015), 'overlapping ecologies' (Liu 2017, Liu 2018) or 'issue ecologies' (Block-Lieb and Halliday 2017).

Professionals in our framework draw on organizational and professional networks at the same time, building alliances where they can to control how issues are treated. While others prefer to describe professionals as operating in organizational fields, we stress that both professionals and organizations have 
agency in forming strategies, and that neither provides a passive space for the other to operate within. As such, professionals will seek to extend their networks through common identification with other similarly trained professionals, though often not through formal professional associations, or by creating alliances with professionals with different but complementary sets of skills. By doing so they can engage in 'epistemic arbitrage' between different pools of professional knowledge and be seen as important brokers of knowledge on the issue of concern within the professional and organizational network (Seabrooke 2014). Professionals engaging in this kind of activity often do so beyond their organizations, which provide opportunities for network building but rarely oversee all activities in which those tasked with work engage.

We propose that a professional-organizational two-level network permits us to look at relations between two different sets of actors when it comes to processes of issue control. Our two-level network consists of professional networks that are inter-personal, built throughout careers on issue-specific work, and organizational networks that exist where alliances are formed between organizations. TBGls occur within such two-level networks.

Figure 1: Professional-Organizational Two-Level Network

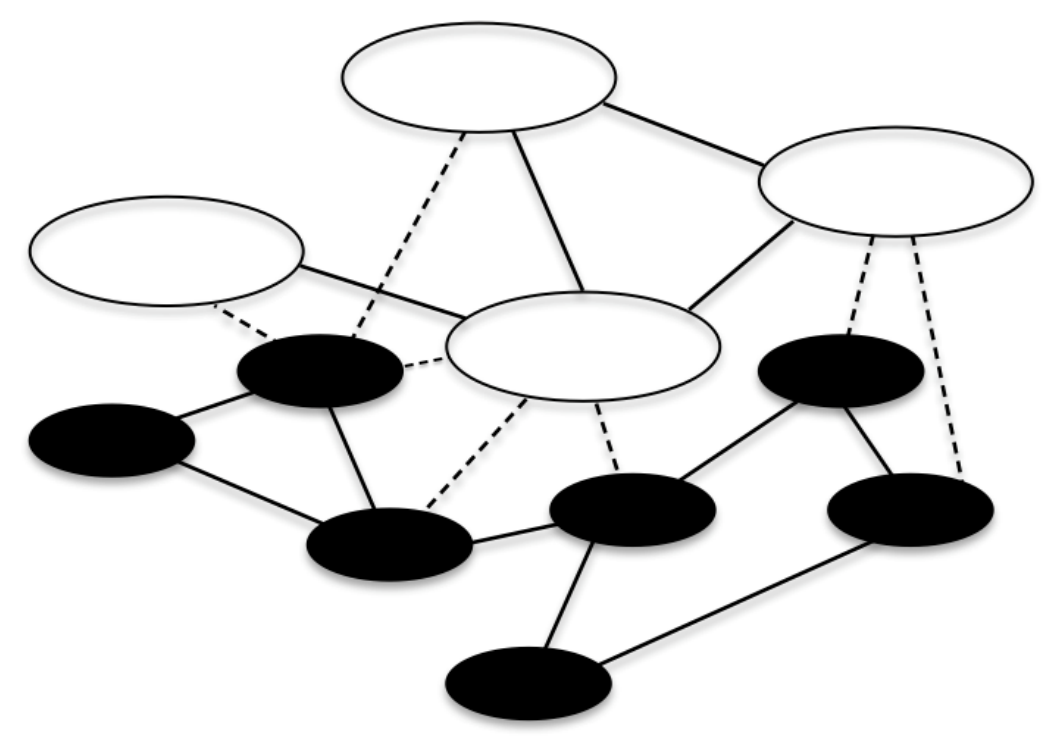

Source: Henriksen and Seabrooke 2016.

Figure 1 depicts a simple two-level network that is involved in organizing a particular transnational issue. At the top are organizations (the white discs), which are networked, with the one on the far left the most isolated and the one in the center the most connected. Below the organizations are issue professionals (the black discs), who have their own network. The professional on the far left is the least connected and the professional on the center right the most. Dashed lines between the professionals and the organizations represented ties between the two levels. In this example the professional in the upper left is linked to three organizations, while those on the far left and bottom are connected to no organizations but are connected to other professionals. On this hypothetical transnational issue the professional with three ties to organizations may have a lot of influence on how the issue is treated and how tasks are allocated.

Within such two-level networks prominent professionals are often 'multiple insiders' (Vedres and Stark 2010) through common work teams, event attendance, involvement in expert groups and committees, and so forth, through which they build their issue-specific personal networks, but also get access to varied organizational contexts. These professionals inhabit similar 'thought worlds' across different organizational contexts (Vad Baunsgaard and Clegg 2013). 
Organizations also attempt to control issues and have a range of strategies at their disposal. An obvious one is to increase the technicality of the issue to fend off competitors (Büthe and Mattli 2011). If organizations can control what is considered to be legitimate expertise on an issue, or if they coordinate professional and organizational networks tightly then this strategy can work. Global professional service firms, for example, are highly integrated and seek to control particular issues through their knowledge management systems (Boussebaa 2009). However, if such control is not possible then organizations need to engage in framing contests to try and control how issues are treated (Hasselbalch and Seabrooke 2018). Once there is a contest, professionals have a range of options to increase their own autonomy and propose views that run counter to organizational interests.

Describing the professional-organizational nexus as a two-level network allows us to consider how professionals and organizations take positions on particular issues relative to their peers, as well as the character of the ties between those involved in TBGIs. Our focus is on professional and organizational interaction within networks, and network theory is important in providing a foundation for understanding different types of behavior.

A key lesson from network analysts is that the formation of social alliances in attempts to achieve control comes from patterns of interaction in which individuals and organizations are embedded (Granovetter 1985; Bearman 1993, p. 10; Wellmann et al. 1997; Emirbayer 1997). A network is a set of actors, or nodes, along with a set of ties, the relations that connect them. Relations in networks interconnect through shared points and form paths that indirectly link actors that would otherwise not be directly related. This conception enables a view of a network as a connected system, linking local behaviors to the system as a whole. A great deal of network analysis is concerned with characterizing network structures, how actors are positioned within them. Network theory makes claims about the mechanisms and processes that interact with a network structure to allow certain actors in the network to act (Borgatti and Halgin 2011). In general, a network view of strategy pays attention to the flow of knowledge and resources between professionals and organizations and the strategic behavior emerging from their attempts to gain control over the ongoing distribution patterns within these flows.

Two-level networks also exhibit so-called 'small world' characteristics that have implications for the strategies of issue control that professionals and organizations may pursue. The idea of a small world comes from the observation that actors in a 'big world' often experience themselves as being surprisingly close to each other (Watts 1999). Transnational professional networks have large geographical distances and the number of individuals and organizations doing work may be in the hundreds or thousands. The social distances across which organizing must be performed are complex. Creating ties to central organizations can generate what has been called 'global microstructures' (Knorr Cetina and Bruegger 2002), which often build on established frameworks that permit interpersonal ties to flourish and establish behavioral rules. Within these networks small world characteristics can emerge, with networks clustered around particular organizational alliances or professional communities. Professionals can use their skills and knowledge to shape the way organizations treat and organize issues within the network (Kroeger 2011; Seabrooke 2014).

How professionals connect is also important to understand. This may be through events, conferences, and workshops to which we normally attribute little importance, but which can be crucial for establishing how issues are treated and who controls contributing knowledge (Lampel and Meyer 2008). The use of such events to share business cards and contacts, and establish connections on social media, may seem unimportant, but can be useful in establishing 'weak ties' to actors who are at a greater social distance (Granovetter 1973). This is one of the reasons organizations value professionals who can demonstrate high job mobility, and why professionals seek out new opportunities, with many persistently 'on the market' (see Auld and Renckens, Chapter 6, for analysis of this mobility).

Professionals who change positions a lot or are not tied to particular organizations run the risk of being seen as weak but broad in their embedding strategy across two-level networks. The contrary opinion is that when this behavior is done successfully it can contribute to 'robust action' that allows influence across networks to be greater (Padgett and Ansell 1993, Bothner et al. 2010). Studies in organizational sociology 
have demonstrated that those credited with good ideas are often actors occupying sparse network regions abundant with 'structural holes' (Burt 2004). Structural holes are network locations where two nodes are disconnected, which offers an opportunity for a third node to bridge the gap and gain control of the flow of information between the disconnected nodes. Where network densities are comparatively low, exploiting disconnections can be a successful strategy for organizations and professionals working to change perceptions on particular issues. Where network densities are comparatively high, organizations or professionals can exercise tighter control over how issues are treated.

Our aim here is not to provide an exhaustive account of network theories, but to demonstrate that the structural properties of networks are important in understanding how agents can behave and how transnational business governance interactions exhibit two-level dynamics.

\section{Matching Professional and Organizational Characteristics}

Our general advice to scholars researching TBGIs is to be wary about assuming the location and form of organizational action. We agree with others who have stressed the dangers of organizational nominalism and the need for a 'relational turn' in sociology (Emirbayer 1997). Of course there are limits. Rather than everything being relational, our proposal is that understanding interactions within a two-level professional and organizational network is useful. This allows us to trace TBGIs and hybrid forms of governance while also keeping in mind the professional and organizational strategies at play.

Professional strategies will undoubtedly vary, with some aligning well with organizational strategies, while in other cases professionals will work against or around organizations. In our framework organizational networks provide opportunities, and the scope of opportunities is also informed by organizational characteristics.

If we are to match up professionals to organizational characteristics in TBGls then we first need to relax some assumptions that are common in various strands of literature. First of all, the sociology of professions literature tells us that professions fight for jurisdictional control over how issues are treated, and who can work on them (Abbott 1988). This body of work also tells us that professionalism provides a 'third logic' compared to that of bureaucracy or the market (Freidson 2001). The assumption of sealed and siloed professions can be challenged when it comes to investigating TBGIs. As the contributors to this volume show, national professional associations are not commonly invoked to organize transnational standards, rules, and norms. While they may be involved in select cases, such cases are the exceptions rather than commonplace.

Another assumption that must be relaxed is that the denomination of organizational types provides a useful shorthand in telling us what the organization actually does. We know from the literature in international relations that states design international organizations and give them clear mandates that dominant member states expect them to fulfil (Koremenos, Lipson and Snidal 2001). We know that passionate norm entrepreneurs and civil society networks inform how NGOs behave (Keck and Sikkink 1998). And we know that business firms want control above all other things, including profit (Fligstein 1996). But these insights need to be investigated on an ongoing basis and should not be treated as core assumptions. This is important because organizations are rarely silos, and have internal fights. For example, sustainability managers may struggle with procurement managers to control purchasing agendas and influence C-suite executives in lead firms (Meidinger, Chapter 3). Conflicts between mandated objectives, professional norms and science are common within international organizations and NGOs, and strongly inform how policy scripts are created (Kentikelenis and Seabrooke 2017). We should expect such conflicts to exist in organizations involved in TBGIs. Our professional-organizational nexus concept helps us to identify such contests over what we refer to as issue control.

Our two-level network is a useful conceptual device here to pick apart how the hurdles identified in this book arise and what can be done about them. Understanding different types of organizational characteristics is also important in explaining how organizational form does not determine organizational behavior within professional-organizational networks. 
Organizational forms and logics can be differentiated by five characteristics that become increasingly important as competition within professional networks intensifies:

1. Scope

2. Autonomy

3. Resources

4. Staffing

5. Knowledge Centralization

Scope is the narrowness or breadth of an organization's mandate. This can vary widely, with organizations such as Greenpeace, the World Bank, and Unilever having wide mandates. The professionalorganizational networks in which such organizations work are likely to have many structural holes for professionals to exploit. By contrast, narrower mandates of organizations such as the Bank for International Settlements (BIS) and Tax Justice Network will require more specialized tactics from professionals seeking issue control (Ban et al. 2016; Seabrooke \& Wigan 2016).

Autonomy refers to the level of independence organizations have from their principals. This is important in determining how much slack and slippage there is between the organization and its principals, where greater autonomy provides professionals internal and external to the organization greater opportunities for issue control.

Resources refers to how organizations acquire resources to fund their activities. Where organizations rely on membership subscriptions, the definition of what counts as core resources and targeted resources is important for professional and organizational activity. This definition varies widely across international organizations and NGOs. Where the organization is able to raise its own funding, professional autonomy is also likely to increase or be matched to sources other than the subscription base or principal. A contrast can be drawn between the United Nations Development Programme (UNDP) and the United Nations Office for Project Services (UNOPS), where the latter is self-funding and acts very much like a firm compared to the former, which is heavily embroiled in UN bureaucratic politics.

Staffing refers to the organization's openness in hiring professionals, especially staff on ongoing as opposed to project-specific contracts. This is important in determining how departments, units and work teams are composed. This can also vary across organizational forms, with international organizations and NGOs often constrained to hire from subscribing member states or chapters, which can distort how issues are controlled within the organization (Chorev 2012). Firms are not immune to these issues as well, with often a strong bias in hiring to conform to established routines and status perceptions (Lupu and Empson 2015). Even in organizations that are assumed to have tight control over their professional staff, such as the International Monetary Fund, there are cases where the use of external experts has been important in how issues are controlled (Seabrooke and Nilsson 2015).

Knowledge Centralization refers to the degree of knowledge centralization within the organization on the issue it seeks to control. This also applies to international organizations, NGOs, and firms. In some cases activist groups have in-house expertise on particular specialist issues and their professional strategies operate from that basis (Seabrooke and Wigan 2015). However, it is more common that large campaigning NGOs do not have the expertise to produce knowledge on issues, and thus rely on external experts to produce results for them to use (Stroup and Wong 2017). This same dynamic applies to international organizations and firms, which differ strongly on whether they can produce their own knowledge on issues as they attempt to control them. Variations in this dynamic obviously provide opportunities for professionals.

Finally, we suggest that thinking through these organizational characteristics helps us to identify professional strategies involved in TBGls. This framework can be especially useful in thinking through the hurdles identified at the start of this chapter: gaps between policy design and implementation; the use of standard setting bodies as arenas for competing interests; clear power asymmetries in standards and best practices; and the autonomy and mobility of professionals that can undermine the fidelity of standards. All of these hurdles can be understood as outcomes of professional and organizational strategies within and across their respective networks. Our professional-organizational nexus framework offers some insights into 
how TBGIs play out and the likely hurdles they encounter. Identifying these dynamics is important to troubleshoot where interactions deviate from their intention of advancing marginalized actors, promoting sound standards, and advancing better regulation.

'Errol Meidinger's study of the emerging profession of sustainable supply chain management (SSCM) is a vivid illustration of this phenomenon (Chapter 3). 


\section{References}

Abbott, A. (1988), The system of professions: An essay on the division of expert labor, Chicago: University of Chicago Press.

Ban, C., L. Seabrooke, and S. Freitas (2016), 'Grey matter in shadow banking: international organizations and expert strategies in global financial governance', Review of International Political Economy, 23 (6), 1001-1033.

Bearman, P. (1993), Relations into rhetorics: Local elite social structure in Norfolk, England, 1540-1640, New Brunswick, NJ: Rutgers University Press.

Block-Lieb, S. and T.C. Halliday (2017), Global lawmakers: International organizations in the crafting of world markets Cambridge UK: Cambridge University Press.

Blok, A., M.D. Lindstrøm, M.L. Meilvang, and I.K. Pedersen (2018), 'Trans-local professional projects: Rescaling the linked ecology of expert jurisdictions', Journal of Professions and Organization, 5 (2), 106122.

Borgatti, S.P. And D.S. Halgin (2011), 'On network theory', Organization Science, 22 (5), 1168-1181.

Bothner, M.S., E.B. Smith and H.C. White (2010), 'A model of robust positions in social networks', American Journal of Sociology, 116 (3), 943-92.

Boussebaa, M. (2009), 'Struggling to organize across national borders: The case of global resource management in professional service firms', Human Relations, 62 (6), 829-850.

Brivot, M. (2011) 'Controls of knowledge production, sharing and use in bureaucratized professional service firms', Organization Studies, 32 (4), 489-508.

Brock, D.M. (2016), 'Professionals and their workplaces in emerging markets-a research agenda', International Journal of Emerging Markets, 11 (3), 460-472.

Burt, R.S. (2004), 'Structural holes and good ideas', American Journal of Sociology, 110 (2), 349-399.

---- (2010), Neighbor networks: Competitive advantage local and personal', Oxford: Oxford University Press.

Büthe, T. and W. Mattli (2011), The new global rulers: The privatization of regulation in the world economy, Princeton: Princeton University Press.

Carpenter, R.C. (2007), 'Setting the advocacy agenda: Theorizing issue emergence and nonemergence in transnational advocacy networks', International Studies Quarterly, 51 (1), 99-120.

Carter, C., C. Spence and D. Muzio (2015), 'Scoping an agenda for future research into the professions', Accounting, Auditing \& Accountability Journal, 28 (8), 1198-1216.

Chorev, N. (2012), The World Health Organization Between North and South, Ithaca: Cornell University Press.

Dezalay, Y. and B.G. Garth (2016), "Lords of the dance" as double agents: elite actors in and around the legal field', Journal of Professions and Organization, 3 (2), 188-206.

Eberlein, B., K.W. Abbott, J. Black, J., E. Meidinger and S. Wood (2014), 'Transnational business governance interactions: Conceptualization and framework for analysis', Regulation \& Governance, 8 (1), 1-21.

Emirbayer, M. (1997), 'Manifesto for a relational sociology', American Journal of Sociology, 103 (2), 281-317.

Evetts, J. (2013), 'Professionalism: Value and ideology', Current Sociology, 61 (5-6), 778-796.

Eyal, G. (2013), 'For a sociology of expertise: The social origins of the autism epidemic', American Journal of Sociology, 118 (4), 863-907.

Faulconbridge, J. and D. Muzio (2008), 'Organizational professionalism in globalizing law firms', Work, Employment and Society, 22 (1), 7-25.

Finnemore, M. and K. Sikkink (1998), 'International norm dynamics and political change', International Organization, 52 (4), 887-917.

Fligstein, N. (1996), 'Markets as politics: A political-cultural approach to market institutions', American Sociological Review, 61 (4), 656-673.

Freidson, E. (2001), Professionalism, the third logic: On the practice of knowledge. Chicago: University of Chicago Press.

Granovetter, M. (1973), 'The strength of weak ties', American Journal of Sociology, 78 (6), 1360-1380. 
---- (1985), 'Economic action and social structure: The problem of embeddedness', American Journal of Sociology, 91 (3), 481-510.

Harrington, B. (2016), Capital Without Borders. Cambridge, MA: Harvard University Press.

Hasselbalch, J. and L. Seabrooke (2018), 'Professional strategies and enterprise in transnational projects', in Mike Saks and Daniel Muzio (eds.), Professions and Professional Service Firms: Private and Public Sector Enterprises in the Global Economy, Abindgon, UK and New York: Routledge, pp. 46-64)

Helgadóttir, O. (2016), 'The Bocconi boys go to Brussels: Italian economic ideas, professional networks and European austerity', Journal of European Public Policy, 23 (3), 392-409.

Henriksen, L.F. and L. Seabrooke (2016), 'Transnational organizing: Issue professionals in environmental sustainability networks', Organization, 23 (5), 722-741.

Hirschman, D. and E.P. Berman (2014), 'Do economists make policies? On the political effects of economics', Socio-Economic Review, 12 (4), 779-811.

Kentikelenis, A.E. and L. Seabrooke, L. (2017), 'The politics of world polity: script-writing in international organizations', American Sociological Review, 82 (5), 1065-1092.

Koremenos, B., C. Lipson and D. Snidal (2001), 'The rational design of international institutions', International Organization, 55 (4), 761-799.

Knorr Cetina, K. and U. Bruegger (2002), 'Global microstructures: The virtual societies of financial markets', American Journal of Sociology, 107 (4), 905-950.

Kroeger, F. (2012), 'Trusting organizations: the institutionalization of trust in interorganizational relationships', Organization, 19 (6), 743-763.

Lampel, J. and A.D. Meyer (2008), 'Field-configuring events as structuring mechanisms: How conferences, ceremonies, and trade shows constitute new technologies, industries, and markets', Journal of Management Studies, 45 (6), 1025-1035.

Lazega, E. (1992), The Micropolitics of Knowledge: Communication and Indirect Control in Workgroups. New York: de Gruyter.

Lindvall, J. (2009), 'The real but limited influence of expert ideas', World Politics, 61 (4), 703-730.

Liu, S. (2017), 'Overlapping ecologies: professions and development in the rise of legal services in China', Sociology of Development, 3 (3), 212-231.

---- (2018), 'Boundaries and professions: Toward a processual theory of action', Journal of Professions and Organization, 5 (1), 45-57.

Lupu, I. and L. Empson (2015), 'Illusio and overwork: playing the game in the accounting field', Accounting, Auditing and Accountability Journal, 28 (8), 1310-1340.

Nilsson, A. (2017), 'Making norms to tackle global challenges: The role of Intergovernmental Organisations', Research Policy, 46 (1), 171-181.

Noordegraaf, M. (2011a), 'Remaking professionals? How associations and professional education connect professionalism and organizations', Current Sociology, 59 (4), 465-488.

----- (2011b), 'Risky business: How professionals and professional fields (must) deal with organizational issues', Organization Studies, 32 (10), 1349-1371.

Padgett, J.F. and C.K. Ansell (1993), 'Robust Action and the Rise of the Medici, 1400-1434', American Journal of Sociology, 98 (6), 1259-1319.

Postma, J., L. Oldenhof and K. Putters (2015), 'Organized professionalism in healthcare: articulation work by neighbourhood nurses', Journal of Professions and Organization, 2 (1), 61-77.

Seabrooke, L. (2014), 'Epistemic arbitrage: Transnational professional knowledge in action', Journal of Professions and Organization, 1 (1), 49-64.

Seabrooke, L., L.F. Henriksen (eds.) (2017), Professional Networks in Transnational Governance, Cambridge, UK and New York: Cambridge University Press.

Seabrooke, L. and E.R. Nilsson (2015), 'Professional skills in international financial surveillance: assessing change in IMF policy teams', Governance, 28 (2), 237-254. 
Seabrooke, L. and E. Tsingou (2014), 'Distinctions, affiliations, and professional knowledge in financial reform expert groups', Journal of European Public Policy, 21 (3), 389-407.

---- (2015), 'Professional emergence on transnational issues: Linked ecologies on demographic change', Journal of Professions and Organization, 2 (1), 1-18.

---- (2016), 'Bodies of knowledge in reproduction: Epistemic boundaries in the political economy of fertility', New Political Economy, 21 (1), 69-89.

Seabrooke, L. and D. Wigan (2015), 'How Activists Use Benchmarks: Reformist and Revolutionary Benchmarks for Global Economic Justice', Review of International Studies, 41 (5), 887-904.

---- (2016), 'Powering ideas through expertise: professionals in global tax battles', Journal of European Public Policy, 23 (3), 357-374.

Spence, C., A. Sturdy and C. Carter (2018), 'Professionals with borders: The relationship between mobility and transnationalism in global firms', Geoforum, 91, 235-244.

Stroup, S.S. and W.H. Wong (2017), The Authority Trap: Strategic Choices of International NGOs. Ithaca: Cornell University Press.

Vad Baunsgaard, V. and S. Clegg (2013), "Walls or boxes": The effects of professional identity, power and rationality on strategies for cross-functional integration', Organization Studies, 34 (9), 1299-1325.

Vedres, B. and D. Stark (2010), 'Structural folds: Generative disruption in overlapping groups', American Journal of Sociology, 115 (4), 1150-1190.

Watts, D.J. (1999), 'Networks, dynamics, and the small-world phenomenon', American Journal of Sociology, 105 (2), 493-527.

Wellman, B., R.Y.L. Wong, D. Tindall and N. Nazer (1997), 'A decade of network change: Turnover, persistence and stability in personal communities', Social Networks, 19 (1), 27-50. 